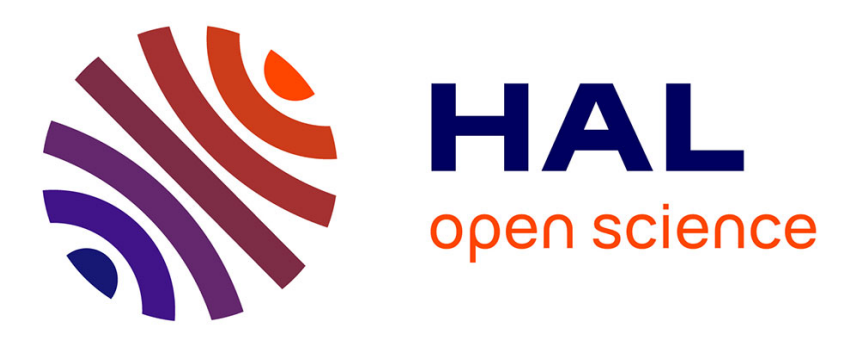

\title{
Lightning contribution to overall whistler mode wave intensities in the plasmasphere
}

J. Záhlava, F. Němec, O. Santolik, I. Kolmašová, G.B. Hospodarsky, Michel Parrot, W.S. Kurth, C. Kletzing

\section{- To cite this version:}

J. Záhlava, F. Němec, O. Santolik, I. Kolmašová, G.B. Hospodarsky, et al.. Lightning contribution to overall whistler mode wave intensities in the plasmasphere. Geophysical Research Letters, 2019, 46 (15), pp.8607-8616. 10.1029/2019GL083918 . insu-02263541

\section{HAL Id: insu-02263541 \\ https://hal-insu.archives-ouvertes.fr/insu-02263541}

Submitted on 6 Sep 2019

HAL is a multi-disciplinary open access archive for the deposit and dissemination of scientific research documents, whether they are published or not. The documents may come from teaching and research institutions in France or abroad, or from public or private research centers.
L'archive ouverte pluridisciplinaire HAL, est destinée au dépôt et à la diffusion de documents scientifiques de niveau recherche, publiés ou non, émanant des établissements d'enseignement et de recherche français ou étrangers, des laboratoires publics ou privés. 


\section{Geophysical Research Letters}

\author{
RESEARCH LETTER \\ 10.1029/2019GL083918 \\ Key Points: \\ - WWLLN data are used to classify \\ spacecraft measurements according \\ to concurrent lightning activity level \\ - Lightning contributes \\ substantially to the overall wave \\ intensity, especially on the \\ afternoon/evening/nightside \\ - Frequencies of these waves start at \\ $500 \mathrm{~Hz}$ with a bandwidth decreasing \\ from 12 to $4 \mathrm{kHz}$ for $L$ between 1.5 \\ and 5
}

Supporting Information:

- Supporting Information S1

Correspondence to:

J. Záhlava,

jan.zahlava@gmail.com

Citation:

Záhlava, J., Němec, F., Santolík, O., Kolmašová, I., Hospodarsky, G. B., Parrot, M., et al. (2019). Lightning contribution to overall whistler mode wave intensities in the plasmasphere. Geophysical Research Letters, 46, 8607-8616. https://doi.org/10.1029/ 2019GL083918

Received 29 MAY 2019 Accepted 24 JUL 2019

Accepted article online 30 JUL 2019 Published online 7 AUG 2019

(C)2019. American Geophysical Union. All Rights Reserved.

\section{Lightning Contribution to Overall Whistler Mode Wave Intensities in the Plasmasphere}

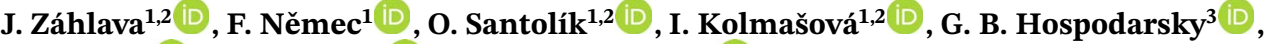 \\ M. Parrot ${ }^{4}$ iD, W. S. Kurth ${ }^{3}$ iD, and C. A. Kletzing ${ }^{3}$ iD \\ ${ }^{1}$ Faculty of Mathematics and Physics, Charles University, Prague, Czech Republic, ${ }^{2}$ Department of Space Physics, \\ Institute of Atmospheric Physics, The Czech Academy of Sciences, Prague, Czech Republic, ${ }^{3}$ Department of Physics and \\ Astronomy, University of Iowa, Iowa City, IA, USA, ${ }^{4}$ LPC2E/CNRS, Orléans, France
}

\begin{abstract}
Electromagnetic waves generated by lightning propagate into the plasmasphere as dispersed whistlers. They can therefore influence the overall wave intensity in space, which, in turn, is important for dynamics of the Van Allen radiation belts. We analyze spacecraft measurements in low-Earth orbit as well as in high-altitude equatorial region, together with a ground-based estimate of lightning activity. We accumulate wave intensities when the spacecraft are magnetically connected to thunderstorms and compare them with measurements obtained when thunderstorms are absent. We show that strong lightning activity substantially affects the wave intensity in a wide range of $L$-shells and altitudes. The effect is observed mainly between $500 \mathrm{~Hz}$ and $4 \mathrm{kHz}$, but its frequency range strongly varies with $L$-shell, extending up to $12 \mathrm{kHz}$ for $L$ lower than 3 . The effect is stronger in the afternoon, evening, and night sectors, consistent with more lightning and easier wave propagation through the ionosphere.
\end{abstract}

Plain Language Summary We analyze contribution of thunderstorms to the intensity of electromagnetic radiation at audible frequencies observed at altitudes between 600 and 32,000 km, where these waves can influence the Van Allen radiation belts. We use the World Wide Lightning Location Network to obtain information about lightning locations and times. Based on that, a lightning activity level is assigned to individual electromagnetic wave measurements of two spacecraft missions: the Detection of Electro-Magnetic Emissions Transmitted from Earthquake Regions and the Van Allen Probes.

Subsequently, we compare median wave intensities obtained at the times of high and low lightning activity. Their ratio reveals that the radio waves originating in strong lightning storms can significantly overpower all other natural waves in a wide range of frequencies and $L$-shells. The strength of this effect substantially depends on the local time. Specifically, it is the best pronounced in the afternoon/evening/night sector and nearly absent in the morning/noon sector. This agrees with the local time dependence of both, lightning occurrence and the wave attenuation in the ionosphere. The observed lightning contribution mainly occurs at frequencies over $500 \mathrm{~Hz}$ and with a bandwidth decreasing from 12 to $4 \mathrm{kHz}$ for $L$ between 1.5 and 5 .

\section{Introduction}

Very low frequency (VLF) electromagnetic waves in the Earth's inner magnetosphere can be generated by wave-particle interactions at larger radial distances, as is, for example, the case of chorus (Allcock, 1957; Oliven \& Gurnett, 1968; Omura et al., 2008; Sazhin \& Hayakawa, 1992; Santolík et al., 2014) or equatorial noise (Boardsen et al., 2016; Gurnett, 1976; Hrbáčková et al., 2015; Russell et al., 1970). Alternatively, they can be of the terrestrial origin, for example, narrowband signals generated by artificial VLF transmitters (Bullough et al., 1975; Cohen \& Inan, 2012; Foster et al., 2016; Gamble et al., 2008; Zhang et al., 2018), by power lines (Bell et al., 1982; Helliwell et al., 1975; Němec et al., 2006), emissions excited artificially in a controlled way, and related triggered emissions (Golkowski et al., 2019; Helliwell, 1974; Omura et al., 1991).

A separate class of electromagnetic emissions of terrestrial origin are wide-band emissions produced by the lightning activity (Storey, 1953). Electromagnetic waves produced by individual lightning strokes (often called spherics) propagating in the Earth-ionosphere waveguide can escape in the whistler mode through the ionosphere and propagate further into the magnetosphere where they can be eventually observed by spacecraft (Al'pert, 1980; Helliwell, 1965; Zheng et al., 2016). They can propagate in a duct formed by a plasma density enhancement, which is usually nearly aligned with the ambient magnetic field, ducting waves at fre- 
quencies below one half of the local electron cyclotron frequency (Helliwell, 1965). Alternatively, the waves can propagate unducted along the trajectory governed by the gradients of refractive index (Bortnik et al., 2003; Hughes, 1981; Maxworth \& Gołkowski, 2017; Santolík et al., 2009; Smith \& Angerami, 1968). The lightning power leaking from the Earth-ionosphere waveguide into the magnetosphere is strongly influenced by ionospheric attenuation and significantly depends on the direction of the local magnetic field and therefore on the geomagnetic latitude. The attenuation peaks at the geomagnetic equator (e.g., Helliwell, 1965), where the direction of the local magnetic field is horizontal. Additionally, the attenuation depends on the ionospheric density profile, which is in the first approximation controlled by the magnetic local time (MLT) with the largest attenuation during the day (Cohen \& Inan, 2012; Cohen et al., 2012; Němec et al., 2008).

Various approaches to estimating the lightning contribution to the wave intensity in the Earth's inner magnetosphere have been used in the past. Lively discussion arose after Green et al. (2005) published their study on the longitudinal dependence of plasmaspheric hiss intensity. Mostly, the affected frequency range was brought into discussion (Meredith et al., 2006; Thorne et al., 2006). This issue was further discussed by Záhlava et al. (2018), who used the Detection of Electro-Magnetic Emissions Transmitted from Earthquake Regions (DEMETER) and Van Allen Probes spacecraft measurements to investigate the longitudinal dependence in more detail showing that a significant lightning contribution extends down to frequencies of about $400 \mathrm{~Hz}$. In particular, this study demonstrates that median wave intensities are significantly larger at geomagnetic longitudes corresponding to the landmass, where the lightning occurrence rate is substantially higher than over the ocean (Said et al., 2013; Zoghzoghy et al., 2015). Colman and Starks (2013) used the lightning occurrence maps provided by the LIS/OTD missions to calculate the approximate lightning power that should be detected by the DEMETER spacecraft at low altitudes. Their power maps are in agreement with DEMETER wave measurements in the $100-\mathrm{Hz}$ band just above $5 \mathrm{kHz}$, exhibiting rather similar diurnal and seasonal variations.

Gemelos et al. (2009) reported a seasonal dependence of energetic electron precipitation over the United States, which they attributed to seasonal variations of lightning activity in the Northern Hemisphere and pitch angle scattering by lightning-generated whistler waves. Němec et al. (2010) indeed obtained higher median wave intensities during the months of high lightning activity. A more precise attempt to resolve the lightning contribution was done by Záhlava et al. (2018), who used the data provided by the neural network for whistler detection onboard the DEMETER spacecraft (Elie et al., 1999; Parrot et al., 2019) to better distinguish various lightning activity levels at the measurement times. All these studies show that the lightning contribution is, especially during the night, nonnegligible. However, downside is the limited ability to estimate the lightning occurrence rate. In the case of Záhlava et al. (2018), the ability of the neural network to detect individual whistlers is unfortunately influenced by the overall wave intensity, being significantly lower at the times of strong natural emissions originating from sources other than lightning. This leads to a systematic bias because the time intervals with strong natural emissions are preferably evaluated as intervals with low whistler rates.

In the present study, we use the World Wide Lightning Location Network (WWLLN), which provides positions, times, and several additional parameters of individual lightning strokes all over the world. This allows us to properly estimate the number of lightning strokes occurring in time intervals and locations corresponding to given DEMETER and Van Allen Probe spacecraft measurements. The use of the two spacecraft missions allows us to compare results obtained at various radial distances. The data sets are described in section 2. Sections 3 and 4 contain the description of the methods and the obtained results. The results are discussed and summarized in section 5.

\section{Data Sets}

WWLLN consists of over 70 stations measuring the electromagnetic field in the frequency range from 6 to $18 \mathrm{kHz}$. If the same waveform is recorded by multiple stations (three or more), it is possible to determine times and locations of individual lightning strokes (Dowden et al., 2002). Unfortunately, the network detection efficiency varies for different locations and times. In order to subtract the dependence on location and local time, hourly maps of the relative detection efficiency are provided along with estimations of lightning energies since April 2009 (Abarca et al., 2010; Hutchins et al., 2012; Hutchins et al., 2012).

VLF measurements of electric and magnetic fields that we analyze in the present paper were performed by two spacecraft missions. The DEMETER spacecraft operated between July 2004 and December 2010 
(Cussac et al., 2006) on a low-altitude ( $\sim 700 \mathrm{~km})$ polar orbit synchronized with the Sun, so that the local time coverage was limited to two distinct local time intervals, one around 10:30 and the other around 22:30. In the Survey mode, which was nearly continuously active at geomagnetic latitudes lower than $65^{\circ}$, one component of the electric field (Berthelier et al., 2006) and one component of the magnetic field (Parrot et al., 2006) were measured and transferred to the ground in the form of frequency-time spectrograms with a time resolution of $2.048 \mathrm{~s}$. The frequency range up to $20 \mathrm{kHz}$ was divided into 1,024 linearly distributed frequency intervals. The magnetic field data suffer from spacecraft interference between 1 and $8 \mathrm{kHz}$, and thus, only the electric field measurements are used in this study. We also restrict the data set to the period between 15 April 2009 and 31 December 2010, when the WWLLN data include the information about the detection efficiency.

The other spacecraft data set is provided by the two identical spacecraft called the Van Allen Probes. They operate on highly elliptic orbits close to the equatorial plane with the perigee altitude of about $600 \mathrm{~km}$ and apogee altitude of about 32,000 km. Due to the orbital precession, the apogee revolves around the Earth and returns to the same local time with a period of approximately 2 years. All six components of the electromagnetic field are measured during $0.5 \mathrm{~s}$ every $6 \mathrm{~s}$ and processed onboard into averaged spectral matrices (Kletzing et al., 2013). Additionally, estimations of the upper hybrid frequency are used to calculate the local plasma number density (Kurth et al., 2015). For this study, the data from the beginning of the mission in August 2012 until the end of 2017 are used.

\section{Methods}

The main motivation of the study is to sort the spacecraft data according to the lightning activity assessed from ground-based detections at the time of spacecraft measurements. For this purpose, the WWLLN data are used. Supporting information Figure S1 shows the color-coded geographic maps of the corrected lightning occurrence rates. We use the inverse values of the network relative detection efficiencies as the correction factors. The average values between 15 April 2009 and the end of 2017 are shown in the MLT windows from 9 to $12 \mathrm{hr}$ and from 21 to $24 \mathrm{hr}$ (roughly corresponding to the DEMETER local time coverage) in supporting information Figures S1a and S1b, respectively. Consistent with former results (e.g., Colman \& Starks, 2013; Rodger et al., 2003), most lightning flashes take place over the landmass and their occurrence is slightly larger in the evening.

The average lightning occurrence rates detected by the WWLLN reach about four flashes per second globally. This, compared to the occurrence rates of about 40 flashes per second obtained from the LIS/OTD observations (Christian et al., 2003; Mach et al., 2011), is consistent with the network efficiency estimated by Abarca et al. (2010), Hutchins et al. (2012), and Rudlosky (2014). For this study, however, the absolute detection efficiency is not crucial, as long as it remains constant during the analyzed time interval. Additionally, the spatial variance of the detection efficiency of the network is accounted for by using the maps of the relative detection efficiency provided in the WWLLN data set.

The lightning activity at times of wave intensity measurements in space was determined in the following way: For each spacecraft data point (time $t$ ), the field line crossing the spacecraft is traced to the top of the ionosphere using the combined International Geomagnetic Reference Field (Thébault et al., 2015) and Tsyganenko89 (Tsyganenko, 1989) magnetic field models. All lightning strokes that occurred in the accumulation time interval from $t-8 \mathrm{~s}$ to $t+2 \mathrm{~s}$ (duration $T=10 \mathrm{~s}$ ) within $3,000 \mathrm{~km}$ from the field line footprints in both hemispheres are taken into account. The time interval was chosen in order to obtain a reasonable amount of strokes, to agree with the time resolution of the spacecraft data, and to account for the wave propagation time. We tried to use various time intervals between -30 and $+10 \mathrm{~s}$ from the spacecraft measurement time and the results changed only marginally. The individual strokes are counted into a summary lightning activity estimator $A(t)$ for all lightning strokes which may affect the spacecraft measurements at time $t$,

$$
A(t)=\frac{1}{K} \sum_{i} k\left(r_{i}\right) / w_{i} ; i:\left(r_{i}<3,000 \mathrm{~km}, t-8 \mathrm{~s}<t_{i}<t+2 \mathrm{~s}\right),
$$

where $K=2 \pi T \int_{0}^{3,000 \mathrm{~km}} k(r) r \mathrm{~d} r$ is a normalization factor introduced to account for the area and accumulation time, $w_{i}$ is the relative detection efficiency of the network at the time $t_{i}$ of the $i$ th lightning detection, and $k\left(r_{i}\right)$ is an attenuation factor accounting for the distance $r_{i}$ between the lightning stroke and the magnetic field line footprints in both hemispheres. This factor was determined based on previous statistical 
a)

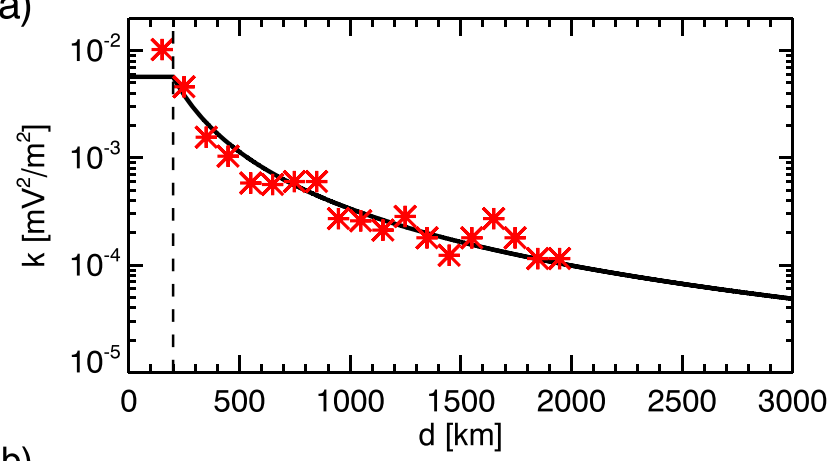

b)

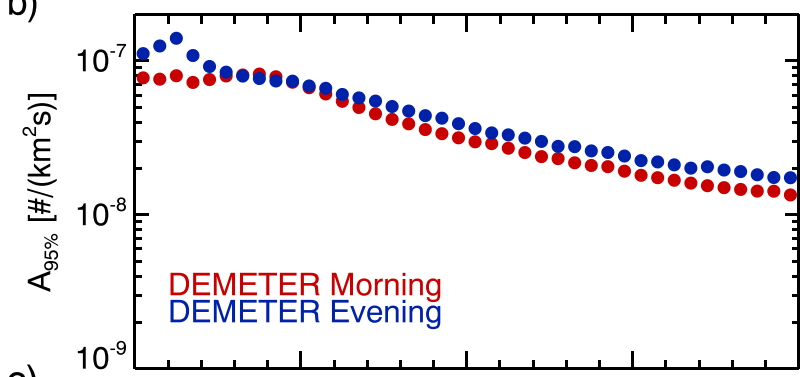

c)

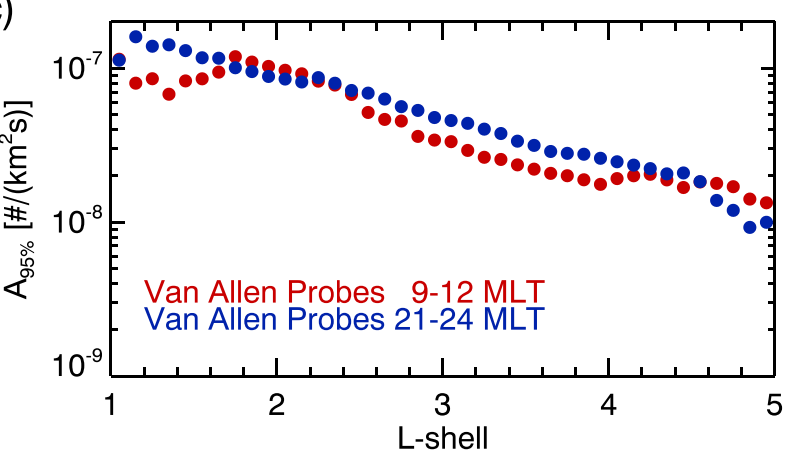

Figure 1. (a) Square of the mean whistler amplitude in low-Earth orbit as a function of the distance from source lightning stroke. Results obtained by Fišer et al. (2010) are shown by the red asterisks. The black curve represents a power law least squares fit. (b, c) High lightning activity thresholds as a function of $L$-shell. (b and c) The thresholds obtained for DEMETER and Van Allen Probes, respectively. The red color corresponds to the morning, and the blue color to the evening results. DEMETER = Detection of Electro-Magnetic Emissions Transmitted from Earthquake Regions.

results. Red asterisks in Figure 1a show the square of the mean whistler amplitude at the low-Earth orbit for daytime-CG flashes observed by Fišer et al. (2010) in their Figure 8, as a function of the distance of the spacecraft magnetic footprint from the source. In a simple approximation, we fitted the data with a power law:

$$
k(r)= \begin{cases}k_{0} \times\left(r / r_{0}\right)^{-1.76}, & \text { for } r>r_{0}, \\ k\left(r_{0}\right), & \text { for } r \leq r_{0},\end{cases}
$$

where $k_{0}=5.7 \times 10^{-3} \mathrm{mV}^{2} / \mathrm{m}^{2}$ and $r_{0}=200 \mathrm{~km}$. The constant value up to $200 \mathrm{~km}$ is justified by the limited accuracy of the field line tracing as well as by a large uncertainty of the mean whistler power calculation at low distances from the source.

One might possibly weight the individual lightning strokes included in the analysis by their energy, but this would introduce undesirable complications, as the lightning energy is sometimes determined with very low accuracy. Rodger et al. (2017) considered only the strokes that suited additional criteria restricting the energy estimation uncertainties. We compared the results obtained using their method of filtering with our approach of plain counts and the results remained nearly unaffected. 


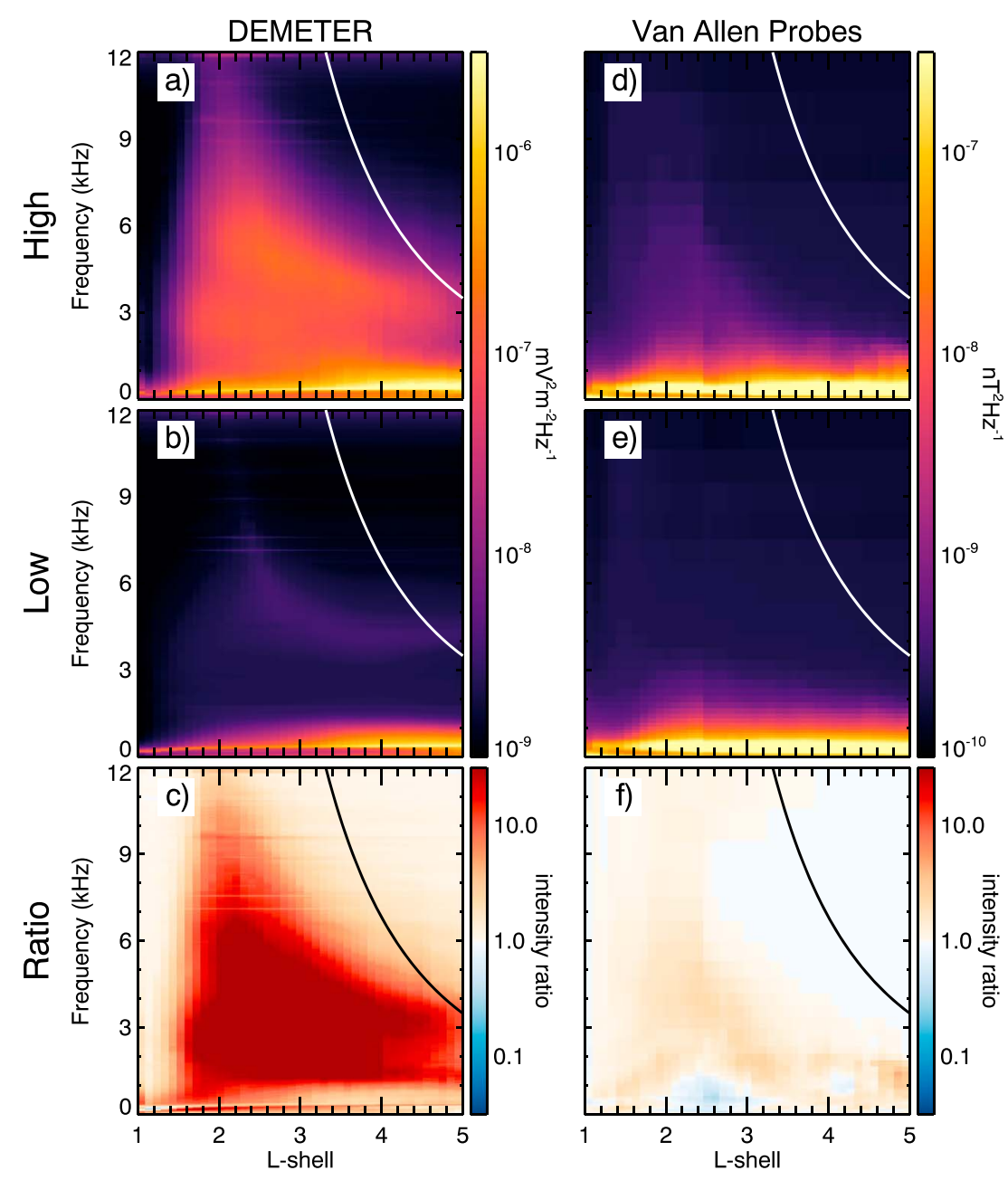

Figure 2. $(\mathrm{a}, \mathrm{b})$ Color-coded median power spectral density of electric field fluctuations measured by the DEMETER spacecraft during the morning side half-orbits at the times of high and low lightning activity, respectively. (c) Ratio between the panels (a) and (b). The red color in panel (c) corresponds to the median wave intensity being larger at the times of high lightning activity than that at the times of low lightning activity. The white color corresponds to the lightning contribution being negligible, and the blue color corresponds to the median wave intensity at the times of low lightning activity being larger than that at the times of high lightning activity. The solid black or white curves mark half of the equatorial electron gyrofrequency calculated using a dipole magnetic field model. (d-f) Same as (a)-(c) but for magnetic field measurements performed by the Van Allen Probes inside the plasmasphere in the MLT interval from 9 to 12 hr. DEMETER = Detection of Electro-Magnetic Emissions Transmitted from Earthquake Regions.

Resulting values of the lightning activity estimator from equation (1) were accumulated for the two spacecraft missions in predefined $L$-shell and MLT bins. The resolution in $L$-shell was set to 0.1. Two MLT intervals were available for the DEMETER spacecraft (morning and evening parts of its orbits). In case of the Van Allen Probes, we used 1-hr MLT intervals. From these accumulated data points, probability distributions of the lightning activity estimator were calculated in the separate L-MLT bins. As robust thresholds for "low" and "high" lightning activity, the 0.05 and 0.95 quantiles of the distributions were used, respectively. The low activity thresholds correspond to zero lightning strokes in all cases. The high activity thresholds are shown in Figures $1 \mathrm{~b}$ and $1 \mathrm{c}$ as a function of $L$-shell for the DEMETER spacecraft and the Van Allen Probes, respectively. The red color represents the morning, and the blue color shows the evening thresholds. Note that in case of the Van Allen Probes, only measurements performed inside the plasmasphere were used, as the lightning contribution was previously shown to be negligible outside the plasmasphere (Záhlava et al., 2018). For this purpose, we define the plasmasphere as a location that meets at least one of the following criteria: (i) $L \leq 2.5$ and (ii) local plasma number density $n \geq 200 \mathrm{~cm}^{-3}$ (Záhlava et al., 2018).

All the obtained thresholds exhibit a rather similar behavior. They peak at low $L$-shells, and they gradually decrease toward larger $L$ values. This is in agreement with the fact that the lightning activity is larger in 


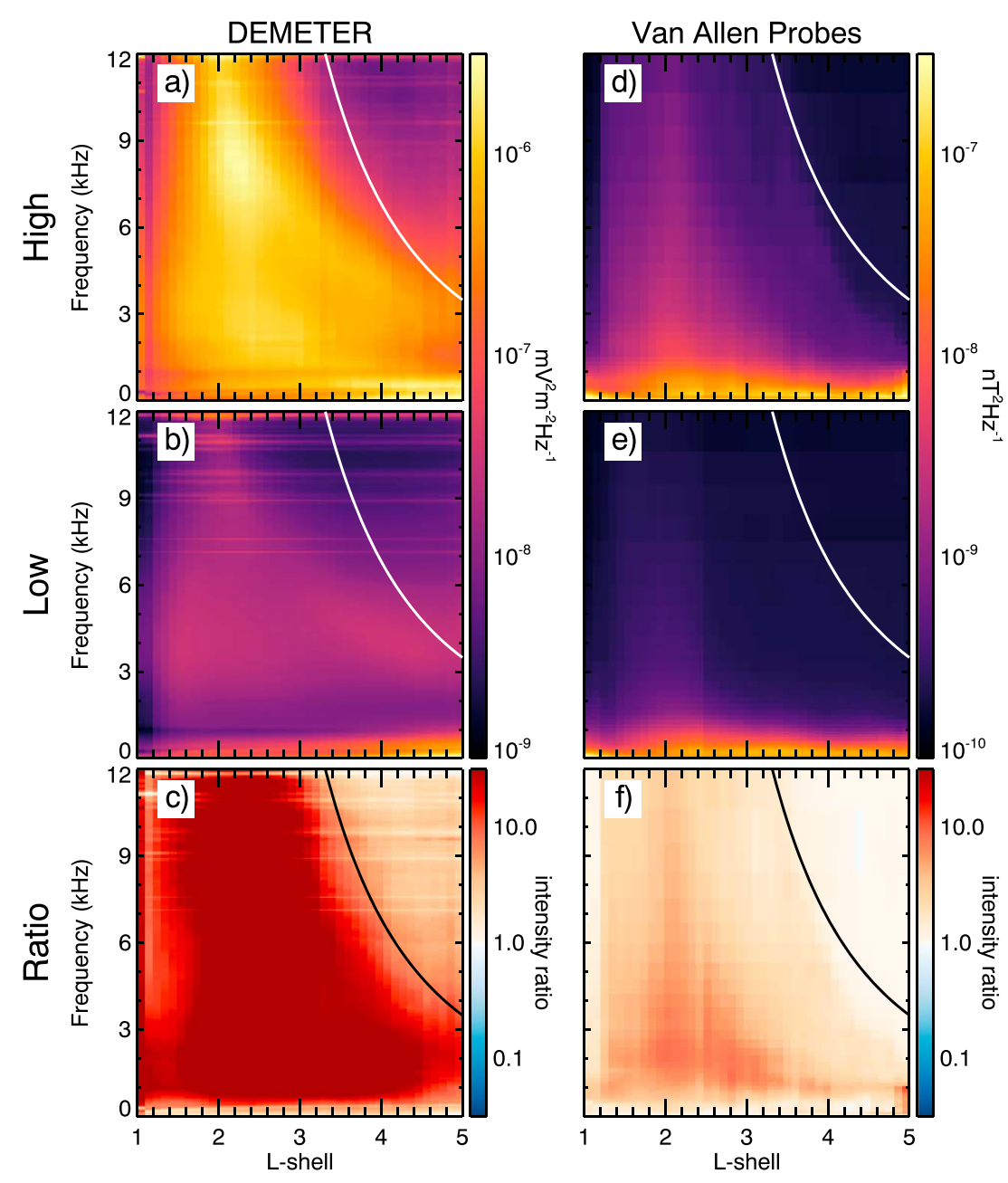

Figure 3. $(a-c)$ Same as Figures $2 a-2 c$ but for the evening side DEMETER half-orbits $(d-f)$ Same as Figures $2 d-2 f$ but for the magnetic local time interval from 21 to $24 \mathrm{hr}$. DEMETER = Detection of Electro-Magnetic Emissions Transmitted from Earthquake Regions.

the proximity of the equator and becomes significantly lower at large latitudes. The evening thresholds are generally slightly higher, consistent with somewhat larger lightning activity during the evening (see supporting information Figure S1). We limit our study only to $L$-shells smaller than 5 . This is motivated by a very low number of orbits with the plasmasphere extended beyond $L=5$.

\section{Results}

We based our analysis on these robust estimators of extremely high or low lightning activity and on the median wave power in space. We chose to use median values, as the power distribution is usually close to log-normal, and median is not influenced by rare events on the tail of the distribution as would be the average value. Figure 2a shows the median power spectral density of electric field fluctuations measured by the DEMETER spacecraft during the morning half-orbits as a function of $L$-shell (abscissa) and wave frequency (ordinate) at the times of high lightning activity. Figure $2 \mathrm{~b}$ shows the median power spectral densities for times of low lightning activity. The intensity ratio is plotted in Figure 2c. The shades of red represent frequency- $L$ regions where high lightning activity coincides with higher median wave power in space than for low lightning activity. White areas are independent of lightning, and the shades of blue mark the frequency- $L$-shell intervals where the median wave intensity is larger at the times of low lightning activity. Note that the intense narrow frequency bands, which are independent of the lightning activity, are related to the man-made signals of VLF transmitters.

Figures $2 \mathrm{~d}-2 \mathrm{f}$ use the same format as Figures $2 \mathrm{a}-2 \mathrm{c}$, but for magnetic field measurements performed by the Van Allen Probes in the MLT interval from 9 to $12 \mathrm{hr}$. These results show nearly the same median wave 


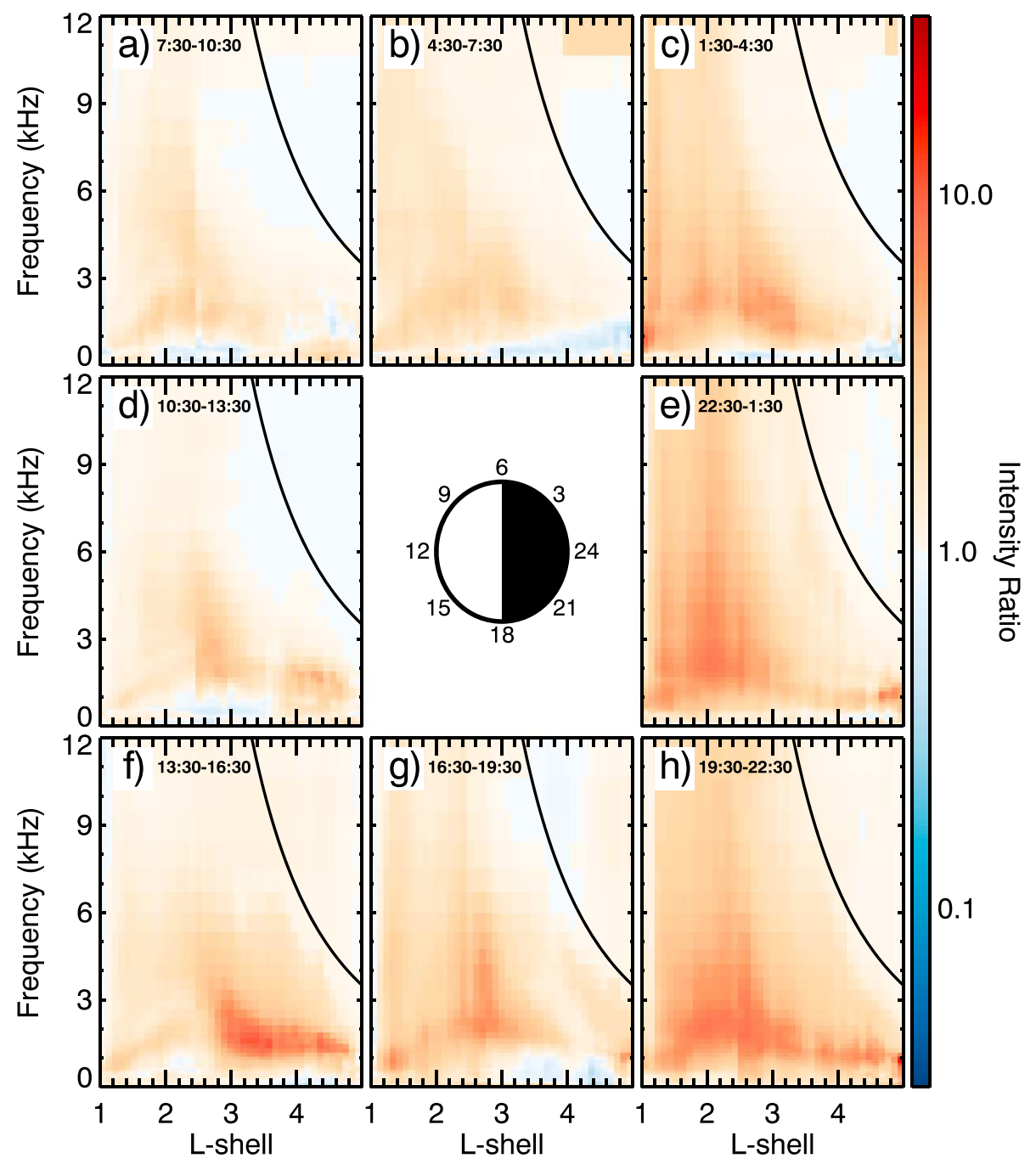

Figure 4. Ratios between median power spectral densities of magnetic field fluctuations measured by the Van Allen Probes inside the plasmasphere at the times of high and low lightning activity. The individual panels were obtained for 3-hr-wide magnetic local time intervals centered at 3, 6, ., $24 \mathrm{hr}$. The color scale has the same meaning as in Figures 2c, 2f, 3c, and $3 \mathrm{f}$.

intensity for high and low lightning activity, unlike the DEMETER results (Figures 2a-2c), which show a rather significant enhancement (on the order of magnitude) of the median wave intensity during high lightning activity at $L$-shells from about 1.5 up to 5 in the frequency range from below $1 \mathrm{kHz}$ up to about 9-10 kHz at $L<3$. The upper frequency limit decreases for larger $L$ values, extending only up to $4 \mathrm{kHz}$ at $L=5$. Strong emissions observed at frequencies below about $1 \mathrm{kHz}$, and larger $L$-shells do not vary significantly with lightning occurrence.

Figure 3 uses the same format as Figure 2, but it shows the results obtained for the evening DEMETER half-orbits and for the MLT interval between 21 and $24 \mathrm{hr}$ in case of the Van Allen Probes. Significant enhancement of median wave intensities correlated with the lightning activity is this time observed by both DEMETER and the Van Allen Probes, still stronger on DEMETER ( 20 times) in comparison with Van Allen Probes ( $\sim 5$ times), both noticeably stronger than for the morning hours. This effect, moreover, covers a larger-frequency range than in the morning, from $\sim 500 \mathrm{~Hz}$ up to $12 \mathrm{kHz}$ at $L<3$. The upper frequency limit again decreases with $L$, to $4 \mathrm{kHz}$ at $L=5$.

Given that the Van Allen Probes spacecraft provide us with a complete MLT coverage, we can analyze the strength of the observed effect as a function of MLT. Figure 4 shows the ratio between the median wave intensities at the times of high and low lightning activity, corresponding thus to Figures $2 \mathrm{f}$ and $3 \mathrm{f}$, but in a 
range of different MLT intervals. Individual plots were obtained for 3-hr intervals centered at 3, 6, .., $24 \mathrm{hr}$. The spatially most extended effect of lightning over a large interval of frequencies is observed in the late evening, namely, in panels centered at 21 and $24 \mathrm{hr}$. The strongest effect of lightning, however, is observed around $15 \mathrm{hr}$ MLT in a limited frequency interval below $2 \mathrm{kHz}$ and at $L$ between 3 and 4.8. This extends to the outer radiation belt, where these waves can cause losses of energetic electrons. On the other hand, the weakest relative contribution of lightning can be observed in the morning sector, where it is also much more restricted in both frequency and $L$.

We also investigated how the median wave intensities vary for different values of AE index (not shown). As expected, the median wave intensities at large $L$-shells and frequencies below about $3 \mathrm{kHz}$ increase with $\mathrm{AE}$ index. However, the ratio between the median wave intensity at the times of high and low lightning activity does not change with AE index.

\section{Discussion and Conclusions}

We have to note that the coincidence of the overall increase of wave intensity with extremely high lightning activity does not directly imply causality. However, no additional third cause, for example, the geomagnetic activity, was found to be responsible for both effects, and the effect of waves on lightning occurrence seems unlikely. Therefore, we assume a causal link from the lightning activity leading to the observed waves in the form of whistlers.

The upper frequency limit of the strong lightning related effect clearly decreases with increasing $L$. On DEMETER this corresponds to increasing latitude. This is an opposite trend compared to the latitudinal evolution of the bandwidth of ionospheric hiss propagating from the magnetosphere and observed by DEMETER (Xia et al., 2019). The observed variations of the frequency bandwidth of lightning related waves therefore cannot be explained by similar propagation effects. During the night, the observed upper frequency limit approximately follows one half of the equatorial electron cyclotron frequency (Figure 3 ). This may suggest that the effect could be linked to ducting by small localized density enhancements (Hanzelka \& Santolík, 2019, and references therein). However, this explanation would require that the main contribution to the wave intensity comes from the lightning whistlers propagating to DEMETER from the magnetically conjugated hemisphere, which disagrees with the intuitive expectation that the whistler power should be the largest in the hemisphere of their origin.

The MLT dependence of the lightning relative contribution shown in Figure 4 follows well the diurnal cycles of lightning activity (see, e.g., Colman \& Starks, 2013) and ionospheric attenuation (see, e.g., Němec et al., 2008). The effect is the largest on the afternoon-evening side. On the other hand, the morning sector is influenced only marginally. The difference between the nightside and dayside is certainly also affected by much lower ionospheric attenuation during the night (Fišer et al., 2010).

In summary, the combination of a robust lightning activity estimator from WWLLN with the Van Allen Probes and the DEMETER spacecraft wave measurements clearly shows the influence of lightning in a broad range of frequencies and $L$-shells. Median wave intensities measured by the two spacecraft missions at the times of high and low lightning activity were compared in order to estimate the frequency- $L$-shell intervals where lightning contributes significantly to the overall wave intensity. The results obtained using the Van Allen Probes in the equatorial plasmasphere show overall lower relative lightning contribution than the results obtained using the DEMETER measurements at low-Earth orbit, probably as a result of a stronger influence of nonlightning emissions (plasmaspheric hiss) in the magnetosphere. We showed that the lightning contribution is significantly stronger on the afternoon to nightside than on the morning and dayside. This follows well the global lightning occurrence that peaks at local times between 14 and $19 \mathrm{hr}$ (Colman \& Starks, 2013). The lightning contribution starts to decrease only at frequencies below about $0.5 \mathrm{kHz}$, where natural nonlightning emissions dominate.

\section{References}

Abarca, S. F., Corbosiero, K. L., \& Galarneau, T. J. (2010). An evaluation of the Worldwide Lightning Location Network (WWLLN) using the National Lightning Detection Network (NLDN) as ground truth. Journal of Geophysical Research, 115, D18206. https://doi.org/10. 1029/2009JD013411

Al'pert, Y. (1980). 40 years of whistlers. Journal of Atmospheric and Terrestrial Physics, 42(1), 1-20. https://doi.org/10.1016/0021-9169 (80)90117-8 
Allcock, G. M. (1957). A study of the audio? Frequency radio phenomenon known as “Dawn Chorus”. Australian Journal of Physics, 10(2), 286-297. https://doi.org/10.1071/PH570286

Bell, T., Luette, J., \& Inan, U. (1982). ISEE 1 observations of VLF line radiation in the Earth's magnetosphere. Journal of Geophysical Research, 87(A5), 3530-3536. https://doi.org/10.1029/JA087iA05p03530

Berthelier, J. J., Godefroy, M., Leblanc, F., Malingre, M., Menvielle, M., Lagoutte, D., et al. (2006). ICE, the electric field experiment on DEMETER. Planetary and Space Science, 54(5), 456-471. https://doi.org/10.1016/j.pss.2005.10.016

Boardsen, S. A., Hospodarsky, G. B., Kletzing, C. A., Engebretson, M. J., Pfaff, R. F., Wygant, J. R., et al. (2016). Survey of the frequency dependent latitudinal distribution of the fast magnetosonic wave mode from Van Allen Probes electric and magnetic field instrument and integrated science waveform receiver plasma wave analysis. Journal of Geophysical Research: Space Physics, 121, 2902-2921. https:// doi.org/10.1002/2015JA021844

Bortnik, J., Inan, U. S., \& Bell, T. F. (2003). Energy distribution and lifetime of magnetospherically reflecting whistlers in the plasmasphere. Journal of Geophysical Research, 108(A5), 1199. https://doi.org/10.1029/2002JA009316

Bullough, K., Denby, M., Gibbons, W., Hughes, A. F. W., Kaiser, T. R., Tatnall, A. R. L., \& King-Hele, D. G. (1975). E.L.F./V.L.F. emissions observed on Ariel 4. Proceedings of the Royal Society of London. A. Mathematical and Physical Sciences, 343, 207-226. https://doi.org/10. 1098/rspa.1975.0060

Christian, H. J., Blakeslee, R. J., Boccippio, D. J., Boeck, W. L., Buechler, D. E., Driscoll, K. T., et al. (2003). Global frequency and distribution of lightning as observed from space by the Optical Transient Detector. Journal of Geophysical Research, 108(D1), 4005. https://doi.org/ 10.1029/2002JD002347

Cohen, M. B., \& Inan, U. S. (2012). Terrestrial VLF transmitter injection into the magnetosphere. Journal of Geophysical Research, 117, A08310. https://doi.org/10.1029/2012JA017992

Cohen, M. B., Lehtinen, N. G., \& Inan, U. S. (2012). Models of ionospheric VLF absorption of powerful ground based transmitters. Geophysical Research Letters, 39, L24101. https://doi.org/10.1029/2012GL054437

Colman, J. J., \& Starks, M. J. (2013). VLF wave intensity in the plasmasphere due to tropospheric lightning. Journal of Geophysical Research: Space Physics, 118, 4471-4482. https://doi.org/10.1002/jgra.50217

Cussac, T., Clair, M. A., Ultré-Guerard, P., Buisson, F., Lassalle-Balier, G., Ledu, M., \& Rey, N. (2006). The DEMETER microsatellite and ground segment. Planetary and Space Science, 54(5), 413-427. https://doi.org/10.1016/j.pss.2005.10.013

Dowden, R. L., Brundell, J. B., \& Rodger, C. J. (2002). VLF lightning location by time of group arrival (TOGA) at multiple sites. Journal of Atmospheric and Solar-Terrestrial Physics, 64(7), 817-830. https://doi.org/10.1016/S1364-6826(02)00085-8

Elie, F., Hayakawa, M., Parrot, M., Pinçon, J. L., \& Lefeuvre, F. (1999). Neural network system for the analysis of transient phenomena on board the DEMETER micro-satellite. IEICE TRANSACTIONS on Fundamentals of Electronics, Communications and Computer Sciences, 82(8), 1575-1581.

Fišer, J., Chum, J., Diendorfer, G., Parrot, M., \& Santolík, O. (2010). Whistler intensities above thunderstorms. In Annales geophysicae, 28, pp. 37-46. https://doi.org/10.5194/angeo-28-37-2010

Foster, J. C., Erickson, P. J., Baker, D. N., Jaynes, A. N., Mishin, E. V., Fennel, J. F., \& Kanekal, S. G. (2016). Observations of the impenetrable barrier, the plasmapause, and the VLF bubble during the 17 March 2015 storm. Journal of Geophysical Research: Space Physics, 121, 5537-5548. https://doi.org/10.1002/2016JA022509

Gamble, R. J., Rodger, C. J., Clilverd, M. A., Sauvaud, J. A., Thomson, N. R., Stewart, S. L., \& Berthelier, J. J. (2008). Radiation belt electron precipitation by man-made VLF transmissions. Journal of Geophysical Research, 113, A10211. https://doi.org/10.1029/2008JA013369

Gemelos, E. S., Inan, U. S., Walt, M., Parrot, M., \& Sauvaud, J. A. (2009). Seasonal dependence of energetic electron precipitation: Evidence for a global role of lightning. Geophysical Research Letters, 36, L21107. https://doi.org/10.1029/2009GL040396

Golkowski, M., Harid, V., \& Hosseini, P. (2019). Review of controlled excitation of nonlinear wave-particle interactions in the magnetosphere. Frontiers in Astronomy and Space Sciences, 6, 2. https://doi.org/10.3389/fspas.2019.00002

Green, J. L., Boardsen, S., Garcia, L., Taylor, W. W. L., Fung, S. F., \& Reinisch, B. W. (2005). On the origin of whistler mode radiation in the plasmasphere. Journal of Geophysical Research, 110, A03201. https://doi.org/10.1029/2004JA010495

Gurnett, D. A. (1976). Plasma wave interactions with energetic ions near the magnetic equator. Journal of Geophysical Research, 81(16), 2765-2770. https://doi.org/10.1029/JA081i016p02765

Hanzelka, M., \& Santolík, O. (2019). Effects of ducting on whistler-mode chorus or exohiss in the outer radiation belt. Geophysical Research Letters, 46, 5735-5745. https://doi.org/10.1029/2019GL083115

Helliwell, R. A. (1965). Whistlers and related ionospheric phenomena (Vol. 50). Stanford: Stanford University Press Stanford.

Helliwell, R. A. (1974). Controlled VLF wave injection experiments in the magnetosphere. Space Science Reviews, 15(6), 781-802. https:// doi.org/10.1007/BF00241061

Helliwell, R. A., Katsufrakis, J. P., Bell, T. F., \& Raghuram, R. (1975). Vlf line radiation in the Earth's magnetosphere and its association with power system radiation. Journal of Geophysical Research, 80(31), 4249-4258. https://doi.org/10.1029/JA080i031p04249

Hrbáčková, Z., Santolík, O., Němec, F., Macúšová, E., \& Cornilleau-Wehrlin, N. (2015). Systematic analysis of occurrence of equatorial noise emissions using 10 years of data from the Cluster mission. Journal of Geophysical Research: Space Physics, 120, 1007-1021. https:// doi.org/10.1002/2014JA020268

Hughes, A. (1981). Satellite measurements of whistler dispersion at low latitudes. Advances in Space Research, 1(1), 377-380. https://doi. org/10.1016/0273-1177(81)90138-1

Hutchins, M. L., Holzworth, R. H., Brundell, J. B., \& Rodger, C. J. (2012). Relative detection efficiency of the World Wide Lightning Location Network. Radio Science, 47, RS6005. https://doi.org/10.1029/2012RS005049

Hutchins, M. L., Holzworth, R. H., Rodger, C. J., \& Brundell, J. B. (2012). Far-field power of lightning strokes as measured by the World Wide Lightning Location Network. Journal of Atmospheric and Oceanic technology, 29(8), 1102-1110. https://doi.org/10.1175/ JTECH-D-11-00174.1

Kletzing, C. A., Kurth, W. S., Acuna, M., MacDowall, R. J., Torbert, R. B., Averkamp, T., et al. (2013). The Electric and Magnetic Field Instrument Suite and Integrated Science (EMFISIS) on RBSP. Space Science Reviews, 179(1-4), 127-181. https://doi.org/10.1007/ s11214-013-9993-6

Kurth, W. S., De Pascuale, S., Faden, J. B., Kletzing, C. A., Hospodarsky, G. B., Thaller, S., \& Wygant, J. R. (2015). Electron densities inferred from plasma wave spectra obtained by the Waves instrument on Van Allen Probes. Journal of Geophysical Research: Space Physics, 120, 904-914. https://doi.org/10.1002/2014JA020857

Mach, D. M., Blakeslee, R. J., \& Bateman, M. G. (2011). Global electric circuit implications of combined aircraft storm electric current measurements and satellite-based diurnal lightning statistics. Journal of Geophysical Research, 116, D05201. https://doi.org/10.1029/ 2010JD014462 
Maxworth, A., \& Gołkowski, M. (2017). Magnetospheric whistler mode ray tracing in a warm background plasma with finite electron and ion temperature. Journal of Geophysical Research: Space Physics, 122, 7323-7335. https://doi.org/10.1002/2016JA023546

Meredith, N. P., Horne, R. B., Clilverd, M. A., Horsfall, D., Thorne, R. M., \& Anderson, R. R. (2006). Origins of plasmaspheric hiss. Journal of Geophysical Research, 111, A09217. https://doi.org/10.1029/2006JA011707

Němec, F., Santolík, O., Parrot, M., \& Berthelier, J. J. (2006). Power Line Harmonic Radiation(PLHR) observed by the DEMETER spacecraft. Journal of Geophysical Research, 111, A04308. https://doi.org/10.1029/2005JA011480

Němec, F., Santolík, O., Parrot, M., \& Bortnik, J. (2008). Power line harmonic radiation observed by satellite: Properties and propagation through the ionosphere. Journal of Geophysical Research, 113, A08317. https://doi.org/10.1029/2008JA013184

Němec, F., Santolík, O., Parrot, M., \& Rodger, C. J. (2010). Relationship between median intensities of electromagnetic emissions in the VLF range and lightning activity. Journal of Geophysical Research, 115, A08315. https://doi.org/10.1029/2010JA015296

Oliven, M., \& Gurnett, D. (1968). Microburst phenomena: 3. An association between microbursts and VLF chorus. Journal of Geophysical Research, 73(7), 2355-2362. https://doi.org/10.1029/JA073i007p02355

Omura, Y., Katoh, Y., \& Summers, D. (2008). Theory and simulation of the generation of whistler-mode chorus. Journal of Geophysical Research, 113, A04223. https://doi.org/10.1029/2007JA012622

Omura, Y., Nunn, D., Matsumoto, H., \& Rycroft, M. J. (1991). A review of observational, theoretical and numerical studies of VLF triggered emissions. Journal of Atmospheric and Terrestrial Physics, 53(5), 351-368. https://doi.org/10.1016/0021-9169(91)90031-2

Parrot, M., Benoist, D., Berthelier, J. J., Blecki, J., Chapuis, Y., Colin, F., et al. (2006). The magnetic field experiment IMSC and its data processing onboard DEMETER: Scientific objectives, description and first results. Planetary and Space Science, 54(5), 441-455. https:// doi.org/10.1016/j.pss.2005.10.015

Parrot, M., Pinçon, J. L., \& Shklyar, D. (2019). Short-fractional hop whistler rate observed by the low-altitude satellite DEMETER at the end of the solar cycle 23. Journal of Geophysical Research: Space Physics, 124, 3522-3531. https://doi.org/10.1029/2018JA026176

Rodger, C. J., Brundell, J. B., Holzworth, R. H., Douma, E., \& Heckman, S. (2017). The World Wide Lightning Location Network (WWLLN): Update on new dataset and improved detection efficiencies. In 32nd URSI GASS. Montreal: URSI GASS.

Rodger, C. J., Clilverd, M. A., \& McCormick, R. J. (2003). Significance of lightning-generated whistlers to inner radiation belt electron lifetimes. Journal of Geophysical Research, 108, 1462. https://doi.org/10.1029/2003JA009906

Rudlosky, S. D. (2014). Evaluating ground-based lightning detection networks using TRMM/LIS observations. In 23rd international lightning detection conference \& 5th international lightning meteorology conference. Helsinki: Vaisala.

Russell, C. T., Holzer, R. E., \& Smith, E. J. (1970). OGO 3 observations of ELF noise in the magnetosphere: 2. The nature of the equatorial noise. Journal of Geophysical Research, 75(4), 755-768. https://doi.org/10.1029/JA075i004p00755

Said, R. K., Cohen, M. B., \& Inan, U. S. (2013). Highly intense lightning over the oceans: Estimated peak currents from global GLD360 observations. Journal of Geophysical Research: Atmospheres, 118, 6905-6915. https://doi.org/10.1002/jgrd.50508

Santolík, O., Macúšová, E., Kolmašová, I., Cornilleau-Wehrlin, N., \& Conchy, Y. (2014). Propagation of lower-band whistler-mode waves in the outer Van Allen belt: Systematic analysis of 11 years of multi-component data from the Cluster spacecraft. Geophysical Research Letters, 41, 2729-2737. https://doi.org/10.1002/2014GL059815

Santolík, O., Parrot, M., Inan, U. S., Burešová, D., Gurnett, D. A., \& Chum, J. (2009). Propagation of unducted whistlers from their source lightning: A case study. Journal of Geophysical Research, 114, A03212. https://doi.org/10.1029/2008JA013776

Sazhin, S. S., \& Hayakawa, M. (1992). Magnetospheric chorus emissions: A review. Planetary and space science, 40(5), 681-697. https:// doi.org/10.1016/0032-0633(92)90009-D

Smith, R. L., \& Angerami, J. J. (1968). Magnetospheric properties deduced from OGO 1 observations of ducted and nonducted whistlers Journal of Geophysical Research, 73, 1-20. https://doi.org/10.1029/JA073i001p00001

Storey, L. R. O. (1953). An investigation of whistling atmospherics. Philosophical Transactions of the Royal Society of London A: Mathematical, Physical and Engineering Sciences, 246(908), 113-141. https://doi.org/10.1098/rsta.1953.0011

Thébault, E., Finlay, C. C., Beggan, C. D., Alken, P., Aubert, J., Barrois, O., et al. (2015). International Geomagnetic Reference Field: The 12th generation. Earth, Planets and Space, 67(1), 79. https://doi.org/10.1186/s40623-015-0228-9

Thorne, R. M., Horne, R. B., \& Meredith, N. P. (2006). On the origin of whistler mode radiation in the plasmasphere" by Green et al. Journal of Geophysical Research, 111, A09210. https://doi.org/10.1029/2005JA011477

Tsyganenko, N. A. (1989). A magnetospheric magnetic field model with a warped tail current sheet. Planetary and Space Science, 37(1), 5-20. https://doi.org/10.1016/0032-0633(89)90066-4

Xia, Z., Chen, L., Zhima, Z., Santolík, O., Horne, R. B., \& Parrot, M. (2019). Statistical characteristics of ionospheric hiss waves. Geophysical Research Letters, 46, 7147-7156. https://doi.org/10.1029/2019GL083275

Záhlava, J., Němec, F., Pinçon, J. L., Santolík, O., Kolmašová, I., \& Parrot, M. (2018). Whistler influence on the overall VLF wave intensity in the upper ionosphere. Journal of Geophysical Research: Space Physics, 123, 5648-5660. https://doi.org/10.1002/2017JA025137

Záhlava, J., Němec, F., Santolík, O., Kolmašová, I., Hospodarsky, G. B., Parrot, M., \& Kletzing, C. (2018). Longitudinal dependence of whistler mode electromagnetic waves in the Earth's inner magnetosphere. Journal of Geophysical Research: Space Physics, 123 , 6562-6575. https://doi.org/10.1029/2018JA025284

Zhang, Z., Chen, L., Li, X., Xia, Z., Heelis, R. A., \& Horne, R. B. (2018). Observed propagation route of VLF transmitter signals in the magnetosphere. Journal of Geophysical Research: Space Physics, 123, 5528-5537. https://doi.org/10.1029/2018JA025637

Zheng, H., Holzworth, R. H., Brundell, J. B., Jacobson, A. R., Wygant, J. R., Hospodarsky, G. B., \& Bonnell, J. (2016). A statistical study of whistler waves observed by Van Allen Probes (RBSP) and lightning detected by WWLLN. Journal of Geophysical Research: Space Physics, 121, 2067-2079. https://doi.org/10.1002/2015JA022010

Zoghzoghy, F. G., Cohen, M. B., Said, R. K., Lehtinen, N. G., \& Inan, U. S. (2015). Shipborne LF-VLF oceanic lightning observations and modeling. Journal of Geophysical Research: Atmospheres, 120, 10,890-10,902. https://doi.org/10.1002/2015JD023226 